\title{
Facile retro-Dieckmann cleavage of a pink phyllobilin: new type of potential downstream steps of natural chlorophyll breakdown
}

\author{
Chengjie $\mathrm{Li}^{1,2} \cdot$ Bernhard Kräutler ${ }^{1}$ (i)
}

Received: 1 November 2021 / Accepted: 31 January 2022

(c) The Author(s) 2022

\begin{abstract}
In senescent leaves of higher plants, colourless chlorophyll (Chl) catabolites typically accumulate temporarily, and undergo natural oxidation, in part, to yellow- and pink-coloured phyllobilins (PBs). The latter, also classified as phylloroseobilins $(\mathrm{PrBs})$, represent the final currently established products of Chl-breakdown, possibly playing important roles in metabolism. However, PrBs, themselves, do not accumulate in the leaves. Indeed, the original PrB identified, then classified as a pink Chl-catabolite (PiCC), is remarkably instable in methanolic solution. As reported here, PiCC readily converts at room temperature into yellow tetrapyrroles. The deduced main process, a retro-Dieckmann reaction, cleaves open its ring $E$ moiety, the $\alpha$-methoxycarbonyl-cyclopentanone unit characteristic of the Chls and of the natural Chl-derived PBs. This readily occurring reaction of the PiCC represents an unprecedented skeletal transformation of a PB, furnishing a cross-conjugated biladiene with a basic structure more similar to the heme-derived bilins.
\end{abstract}

\section{Graphical abstract}

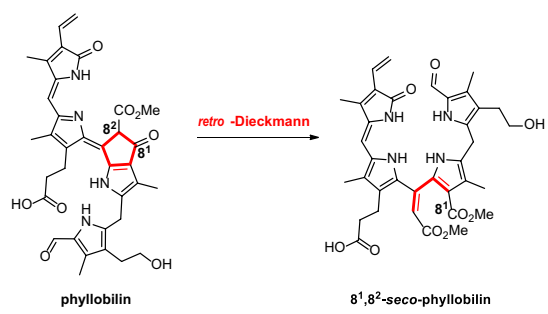

Keywords Chlorophyll $\cdot$ Heterocycle $\cdot$ Pigment $\cdot$ Phyllobilin $\cdot$ Porphyrins $\cdot$ Tetrapyrroles

Dedicated to the memory of Professor Fritz Sauter.

Bernhard Kräutler

bernhard.kraeutler@uibk.ac.at

1 Institute of Organic Chemistry and Center of Molecular Biosciences, University of Innsbruck, Innrain 80/82, 6020 Innsbruck, Austria

2 Key Laboratory for Advanced Materials and Institute of Fine Chemicals, School of Chemistry and Molecular Engineering, East China University of Science and Technology, Meilong Rd 130, Shanghai 200237, China

\section{Introduction}

The characteristic colourful breakdown of chlorophyll (Chl) in fall leaves, an enigma until about 30 years ago [1,2], generates linear tetrapyrroles, named phyllobilins (PBs) [3], via the so-called $\mathrm{PaO}$ /phyllobilin pathway [4-6]. Strikingly, the products of the strictly controlled common early phase of Chl-breakdown are colourless linear tetrapyrroles [5, 7], now classified as phyllobilanes (PBas) [3]. The colourless PBas accumulate in the leaf vacuoles, but, typically, only temporarily [8]. Indeed, PBas were named 'rusty pigments' originally, since their isolates turned rust coloured [9] and PBas convert readily into yellow- and pink-coloured oxidation products, classified as phylloxanthobilins (PxBs) and phylloroseobilins (PrBs), respectively [10]. The yellow 
PxBs also occur in various plants [11-14], generated by a yet hardly investigated metabolic oxidation of corresponding PBas [15]. However, the ubiquitous PxBs are readily oxidized to PrBs, their pink analogues (see Fig. 1) [10, 16, 17], which are, so far, the final fully traceable Chl-breakdown products in senescent leaves $[4,5]$.

The pink Chl-catabolite (PiCC) $\mathbf{1}$ is a PrB found in the fall leaves of the common tree Cercidiphyllum japonicum [10]. The PiCC 1 is prepared via selective chemical oxidation of $\mathrm{Cj}$-NCC-1, the corresponding colourless non-fluorescent Chl-catabolite (NCC) (Fig. 1) [10], a particularly abundant PBa discovered in senescent leaves of $C$. japonicum [18]. In most senescent leaves, neither PBas nor their coloured oxidation products accumulate to a high level, hinting at further, still undefined further breakdown processes of the PBs [5]. Indeed, there have been occasional reports on mono-pyrrolic isolates from senescent leaves [19]. Likewise, mono- and di-pyrrolic compounds originating from chemical destruction of Chl-like precursors were proposed (with little further experimental support) to represent model structures for natural Chl-breakdown [20]. Here, we describe the discovery of the readily occurring cleavage of the natural $\operatorname{PrB} 1$ at its characteristic Chl-derived ring E in methanol [21]. The main such process at this sterically congested $\beta$-ketoester moiety is a retro-Dieckmann reaction, which cleaves open the peripheral $\mathrm{C}-\mathrm{C}$ bond of the ring $E$ moiety, eliminating the structural Chl-derived hallmark that distinguishes the natural PBs decisively from the related heme-derived 'hemo'-bilins [4].

The detailed analysis of the structure of the PiCC 1 in solution and in the crystal [16] has revealed a remarkably extended conjugated $\pi$-system featuring its two unsaturated meso-positions ( $\mathrm{C} 10$ and $\mathrm{C} 15)$ in a 10E,15Z-geometry, as well as notable close non-bonded contacts between peripheral substituents (Figs. 1 and 2). The observed $E$-configuration of the $\mathrm{C} 10=\mathrm{C} 11$ double bond appears to be the result of steric interactions between the substituents at the
C8-C12 periphery [16]. Significant steric strain results from the tight packing of the peripheral substituents in this section of porphyrinoid Chl-precursors, as well. This fact has been used strategically by Woodward in the course of the total synthesis of chlorin-e6-trimethylester, which was known (as Woodward implied) to undergo a Dieckmann condensation furnishing the characteristic $\beta$-ketoester functionality of ring $E$ of the methyl ester of pheophorbide $a$ [22].

Here, we delineate a retro-Dieckmann process at the corresponding $\beta$-ketoester functionality of the naturally occurring Chl-catabolite PiCC 1, readily occurring in methanol and opening up the typical ring $E$ moiety of 1, furnishing the novel, cross-conjugated yellow biladiene 2 (Fig. 2). In fact, we have observed earlier the instability of the PiCC 1 in methanol at room temperature, and its decomposition to yellow products.

\section{Results and discussion}

The PiCC 1 was prepared by air oxidation [16] of the natural yellow Chl-catabolite $C j$-YCC, first isolated from leaves of $C$. japonicum [11]. When solutions of $\mathbf{1}$ in mixtures of $\mathrm{MeOH} / \mathrm{CH}_{2} \mathrm{Cl}_{2}$ were stored for the purpose of obtaining single crystals, the colour of the supernatant was observed to slowly change from red to yellow. Thus, the result of the storage of a methanolic solution of the PiCC $\mathbf{1}$ caught our interest. When kept at room temperature and in the dark, the methanolic solution of $\mathbf{1}$ also underwent a colour change from red to yellow. An HPLC analysis indicated the consumption of 1 in the course of 47 days and its predominant transformation into the slightly more polar fraction of the yellow 2 (see Suppl. Mat. Fig. S1), which features a $\mathrm{UV}-\mathrm{Vis}$ spectrum with an absorption maximum at $465 \mathrm{~nm}$ (see Fig. 3).

In a preparative experiment, an Ar-purged solution of PiCC $1(5.8 \mathrm{mg}, 9.1 \mu \mathrm{mol})$ in $\mathrm{MeOH}\left(58 \mathrm{~cm}^{3}\right)$ was stored

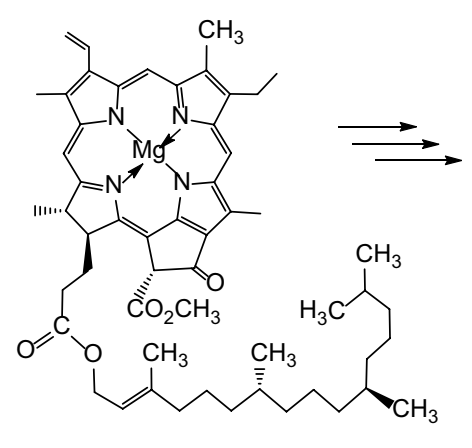

Chlorophyll a

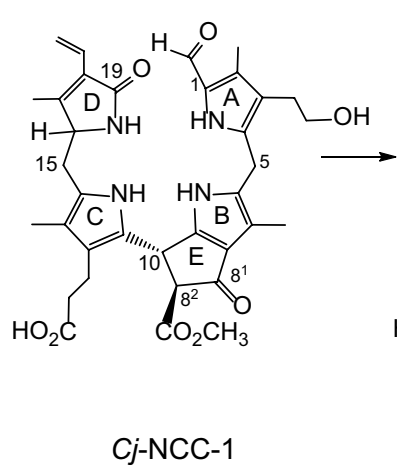

Cj-NCC-1

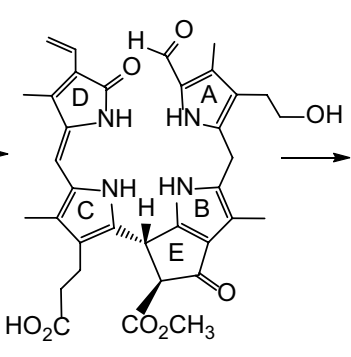

Cj-YCC-2

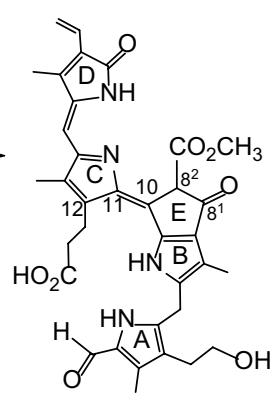

Cj-PiCC 1
Fig. 1 Established stages of chlorophyll breakdown by the common $\mathrm{PaO} /$ phyllobilin pathway. In the fall leaves of the deciduous tree Cercidiphyllum japonicum the colourless Cj-NCC-1 accumulates as the major phyllobilane, from which the yellow phylloxanthobilin $C j$-YCC-2 and the pink phylloroseobilin $C j$-PiCC 1 are generated by subsequent oxidation processes 


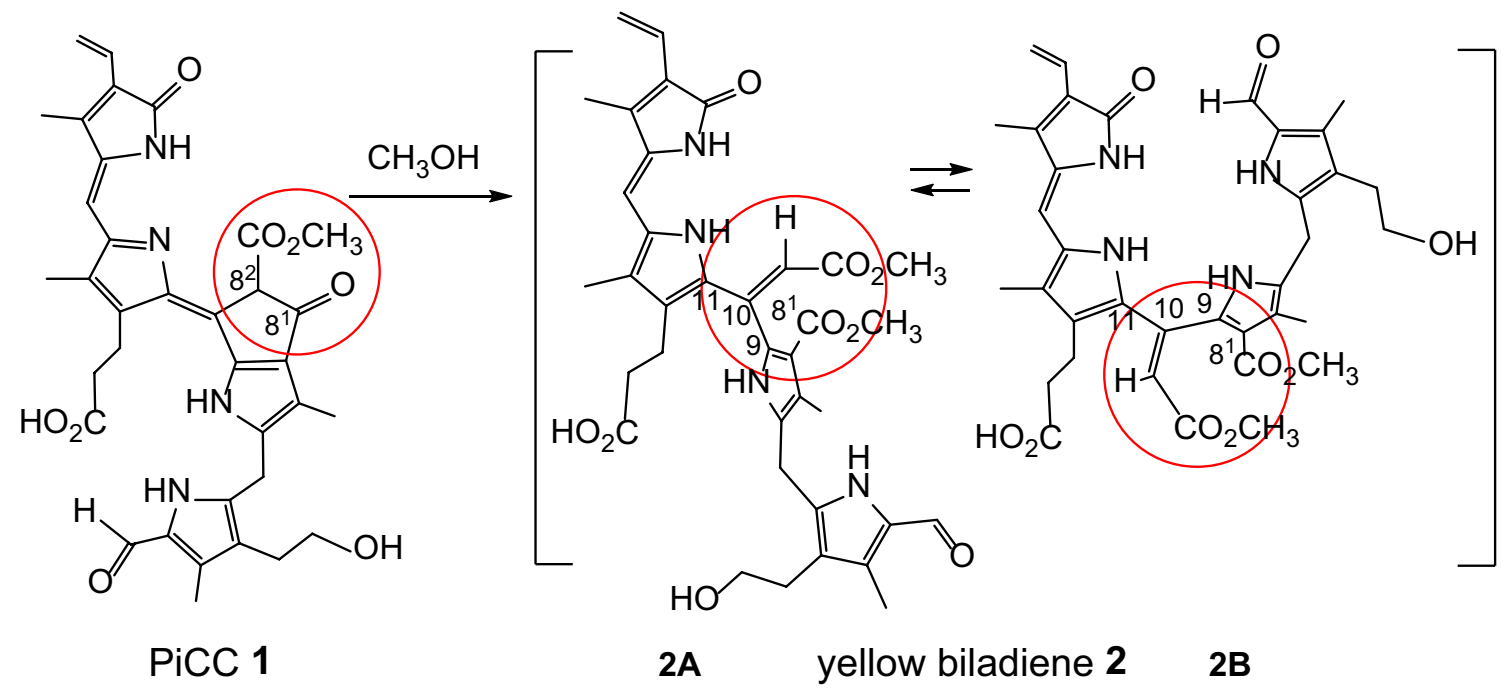

Fig. 2 A retro-Dieckmann reaction in methanolic solution converts the PiCC 1 into the cross-conjugated biladiene 2. In this novel ringopened $8^{1}, 8^{2}$-seco-phyllobilin, the formal single bonds C9-C10-C11 allow for significant conformational flexibility and reduced conjuga-

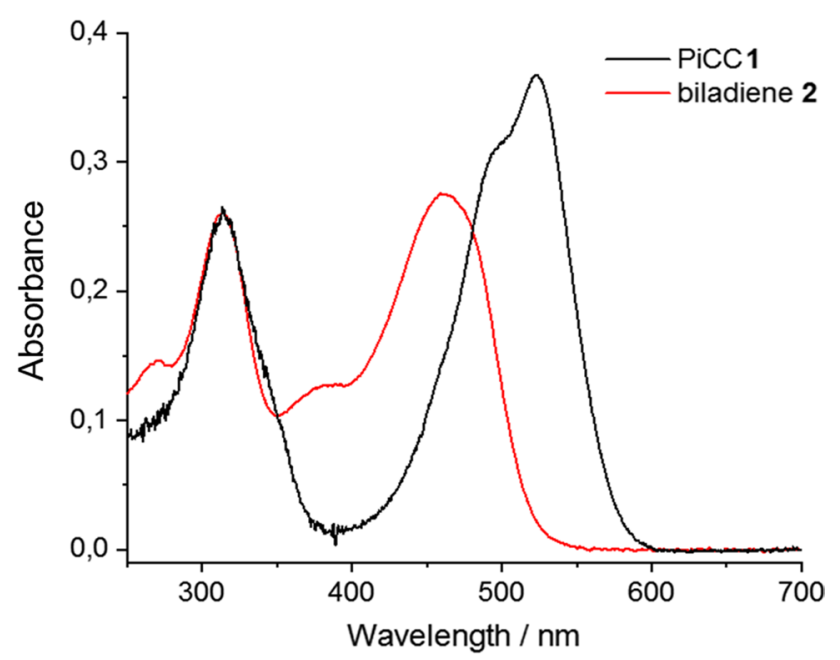

Fig. 3 UV-Vis-absorption spectra of PiCC 1 (in $\mathrm{MeOH}$ ) and of the yellow biladiene 2 (in 3:2 MeOH/50 mM aq. phosphate buffer $\mathrm{pH}$ 7); relative absorbances are given that are normalized at $320 \mathrm{~nm}$

at room temperature in the dark for 19 days. A sample of $53 \mathrm{~cm}^{3}$ of the reaction mixture was subjected to work up, furnishing the yellow decomposition product $\mathbf{2}$ as a major fraction, isolated as $1.8 \mathrm{mg}$ of a yellow residue after drying (32\% yield). In a further preparative experiment, in which a solution of $\mathbf{1}$ in methanol containing $0.08 \%(\mathrm{v} / \mathrm{v})$ of $\mathrm{NEt}_{3}$ was stored at room temperature in the dark, the consumption of $\mathbf{1}$ was roughly five times faster, and was complete after a reaction time of eight days. It furnished tive overlap (the formulae $\mathbf{2 A}$ and $\mathbf{2 B}$ imply conformational isomers with $s$-cis or $s$-trans geometry at the bond $\mathrm{C} 10-\mathrm{C} 11$, and highlight the non-planar nature of the biladiene 2)

2 in a yield of about $53 \%$ (besides about $31 \%$ of the less polar decomposition product 4) (see Suppl. Mat.).

The UV-Vis-absorption spectra of the biladiene $\mathbf{2}$ and of the PiCC 1 are depicted in Figs. 3 and S4. The absorption maximum of 2 at $465 \mathrm{~nm}$ indicates a roughly $60 \mathrm{~nm}$ hypsochromic shift, compared with the corresponding band in the spectrum of PiCC 1 [10]. Hence, the spectra suggest an effective interruption of the main chromophore of the PiCC $\mathbf{1}$ by the transformation to $\mathbf{2}$. An absorption maximum near $315 \mathrm{~nm}$ is also present in both spectra, assigned to ring A, the characteristic $\alpha$-formylpyrrole unit of $\mathbf{1}$ and of the other so-called type-I phyllobilins [3].

In the positive-ion ESI-MS of 2 (Fig. 4), prominent pseudo-molecular ions $[\mathrm{M}+2 \mathrm{Na}+\mathrm{H}]^{+},[\mathrm{M}+\mathrm{Na}]^{+}$, and $[\mathrm{M}+\mathrm{H}]^{+}$were found at $\mathrm{m} / z=717.3,695.3$, and 673.1, respectively, indicating a molecular formula of $\mathrm{C}_{36} \mathrm{H}_{40} \mathrm{~N}_{4} \mathrm{O}_{9}$ from the addition of a $\mathrm{CH}_{3} \mathrm{OH}$ unit to PiCC. Fragmentation experiments indicate cleavage at the $\mathrm{C} 4-\mathrm{C} 5$ and $\mathrm{C} 5-\mathrm{C} 6$ bonds $(\mathrm{m} / z=520$ and 508 , respectively) with a complementary loss of ring A (Fig. S7). Further loss of $\mathrm{MeOH}$ is observed at $m / z=488$ and 476 , respectively. Signals at $\mathrm{m} / z=387$ and 369 indicate di-pyrrolic fragments from the cleavages of the $\mathrm{C} 10-\mathrm{C} 11$ or the $\mathrm{C} 9-\mathrm{C} 10$ bonds that are a diagnostic for the absence of a bond $\mathrm{C} 8^{1}-\mathrm{C} 8^{2}$ in the biladiene 2.

The chemical constitution of the biladiene 2 was established by detailed analysis of its ${ }^{1} \mathrm{H}$-homonuclear and ${ }^{1} \mathrm{H},{ }^{13} \mathrm{C}$-heteronuclear NMR spectra that provided signal assignments for $38 \mathrm{H}$-atoms and $33 \mathrm{C}$-atoms of the biladiene 2 (see Suppl. Mat., Tables S1 and S2). In the $500 \mathrm{MHz}{ }^{1} \mathrm{H}$ NMR spectrum of the yellow biladiene 2 


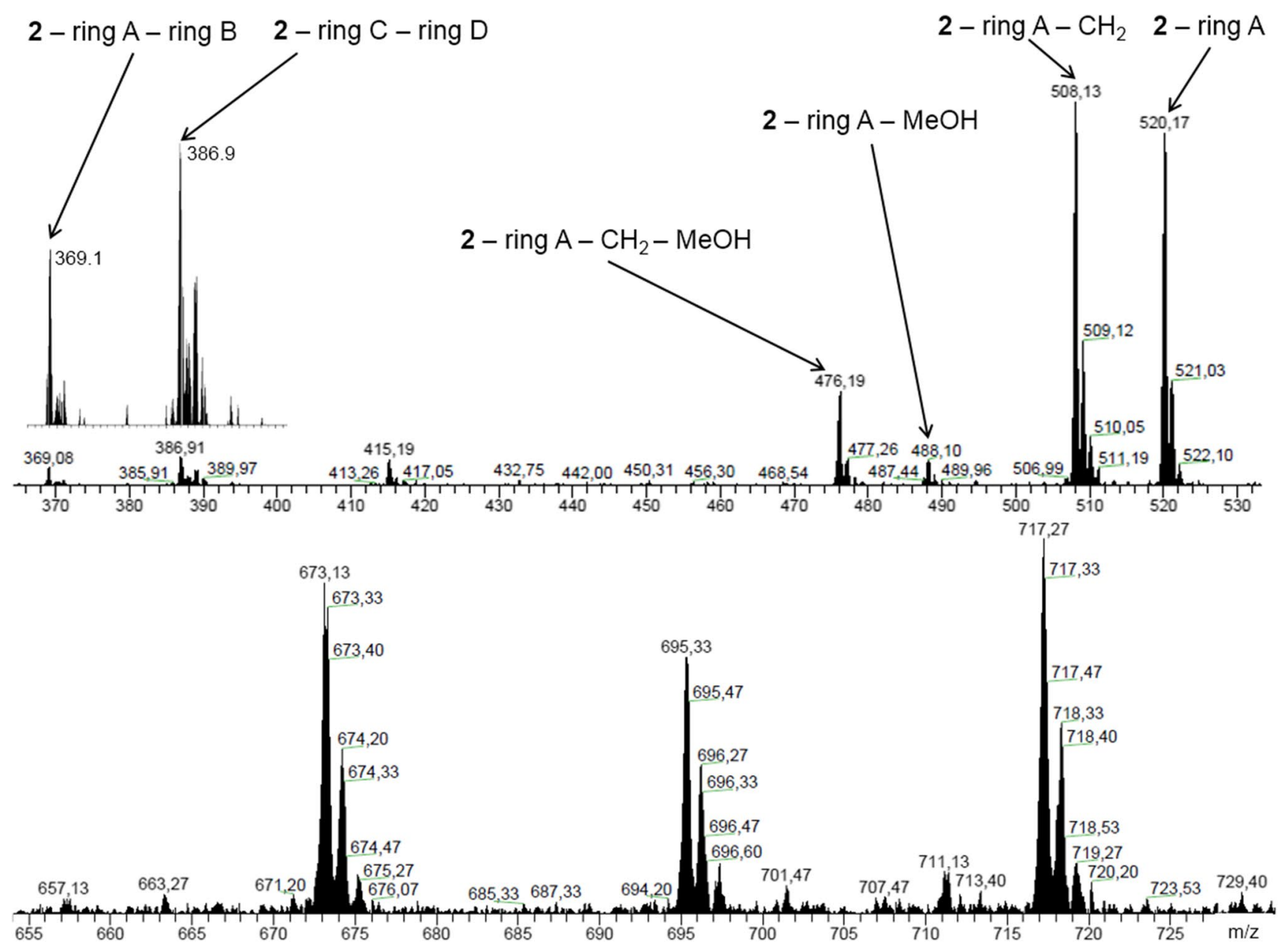

Fig. 4 (+)-Ion ESI-MS analysis of 2 (in $\mathrm{MeOH} /$ aq. $\mathrm{NH}_{4} \mathrm{OAc}$ ). Section of the spectrum of 2 (bottom), and fragments obtained from the pseudomolecular ion at $m / z=673$ by MS/MS (top) (see Suppl. Mat., Fig. S7 for deduced structural presentations of the fragments)

(Fig. 5), signals for the peripheral protons of four methyl groups, a formyl group, a vinyl group, and methylene groups at side chains at $\mathrm{C} 3$ and at $\mathrm{C} 12$ (as well as $4 \mathrm{NHs)}$ stood out and had comparable chemical shifts as the corresponding groups of PiCC 1. Interestingly, at $3.43 \mathrm{ppm}$ and at $3.51 \mathrm{ppm}$, two singlets were observed, each with an integral of 3 protons. In the ${ }^{1} \mathrm{H},{ }^{13} \mathrm{C}$-HSQC spectrum, the singlet at $3.43 \mathrm{ppm}$ coupled with the carbon at $50.8 \mathrm{ppm}$, while the 3.51 signal correlated to the one at $51.4 \mathrm{ppm}$ (Fig. 6), which are typical chemical shifts for ester methyl groups. A further new singlet at $6.17 \mathrm{ppm}$ was found to correlate with an unsaturated carbon at $116.3 \mathrm{ppm}$, indicating a new vinyl group in $\mathbf{2}$. The above results are consistent with the formation of a new ester group and a vinyl group during the decomposition of the PiCC $\mathbf{1}$. In the ${ }^{1} \mathrm{H},{ }^{13} \mathrm{C}-\mathrm{HMBC}$ spectrum, the vinyl proton $\mathrm{HC} 10^{1}$ and the side-chain methylene $\mathrm{H}_{2} \mathrm{C} 12^{1}$ correlate both with C11 of ring C (at 133.4 ppm) (Fig. 6 and Suppl. Mat Fig. $\mathrm{S} 10)$. Thus, the new vinyl group is located at $\mathrm{C} 10$, and the yellow biladiene $\mathbf{2}$ is identified as an unprecedented $8^{1}, 8^{2}$-seco-phyllobilin $\left(8^{1}, 8^{2}\right.$-seco-PB) (Figs. 2 and 6).

Hence, in the methanolic solution, the PiCC 1 had undergone a remarkably facile retro-Dieckmann reaction at ring $E$, a $\mathrm{C}-\mathrm{C}$ bond cleavage that, in the current case, is presumably accelerated by the concurrent formation of the vinyl group $\left(\mathrm{C} 10=\mathrm{C}_{10}{ }^{1}\right)$ in the ring opening step. The deduced cleavage of ring $E$ has also resulted in an increased conformational flexibility that helped to reduce possible steric strain. To deduce the stereochemistry at the new double bond $\left(\mathrm{C} 10=\mathrm{C}_{10} 0^{1}\right)$ of 2 , the correlation of the proton $\mathrm{HC}^{1} 0^{1}$ to the nearby protons in the ROESY spectrum of $\mathbf{2}$ provided critical information. The observed strong coupling between $\mathrm{HC}^{1} 0^{1}$ and $\mathrm{HN} 23$, as well as weaker correlations between $\mathrm{HC} 10^{1}$ and both $\mathrm{H}_{2} \mathrm{C}_{2} 2^{1}$ and $\mathrm{H}_{2} \mathrm{C} 12^{2}$, are all consistent with a (predominant) 10Z-geometry (Figs. 2 and 6).

The deduced structure of the cross-conjugated yellow biladiene 2 indicates its formation by a retro-Dieckmann reaction of the PiCC 1. In a plausible mechanism (Fig. 7), methanol adds to the carbonyl group at $\mathrm{C} 8^{2}$ to afford the 


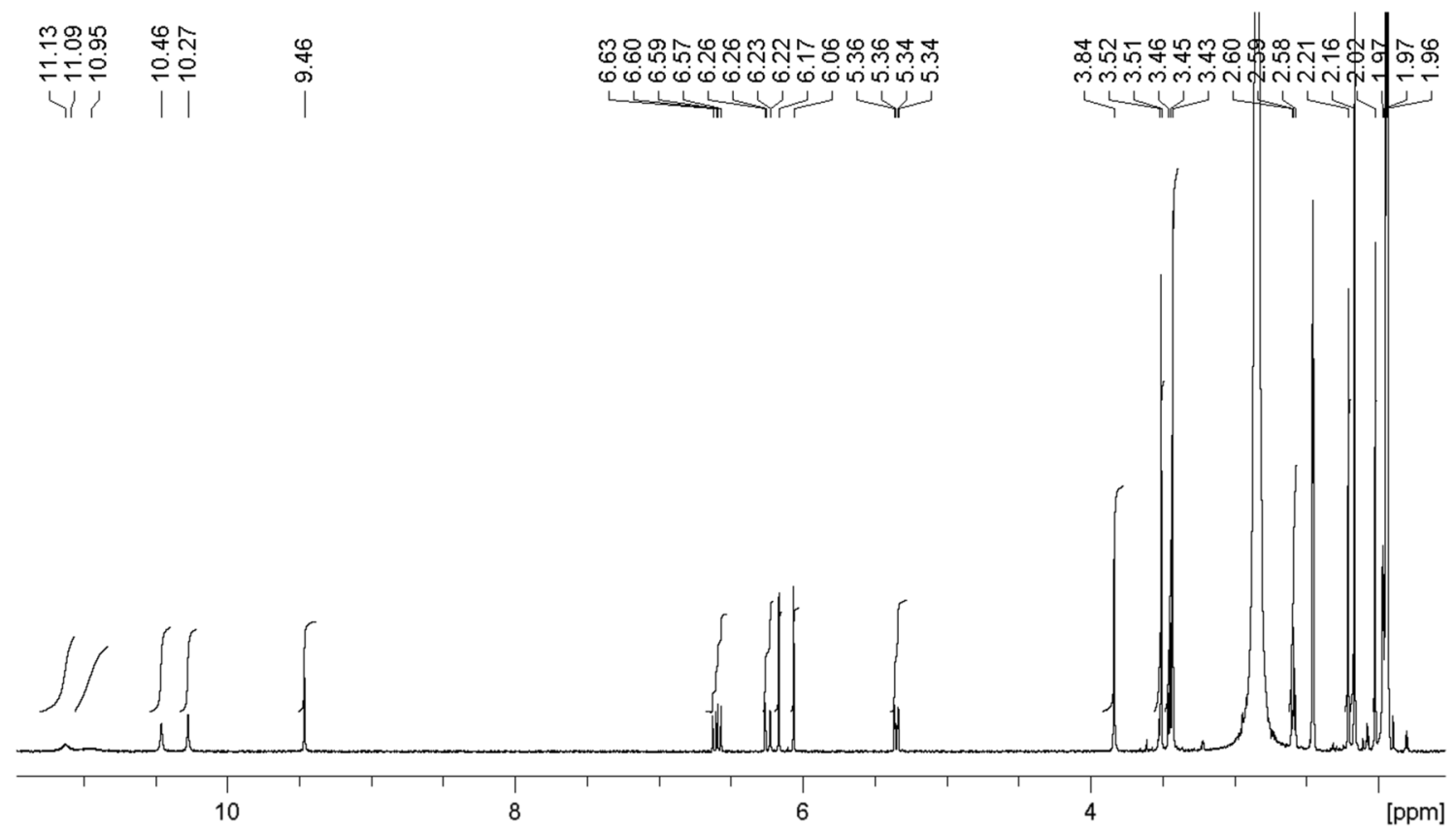

Fig. $5500 \mathrm{MHz}{ }^{1} \mathrm{H}$ NMR spectrum of the yellow biladiene 2 in $\mathrm{CD}_{3} \mathrm{CN} / \mathrm{DMSO}-d_{6}(2: 1, v / v)$ at $25^{\circ} \mathrm{C}$

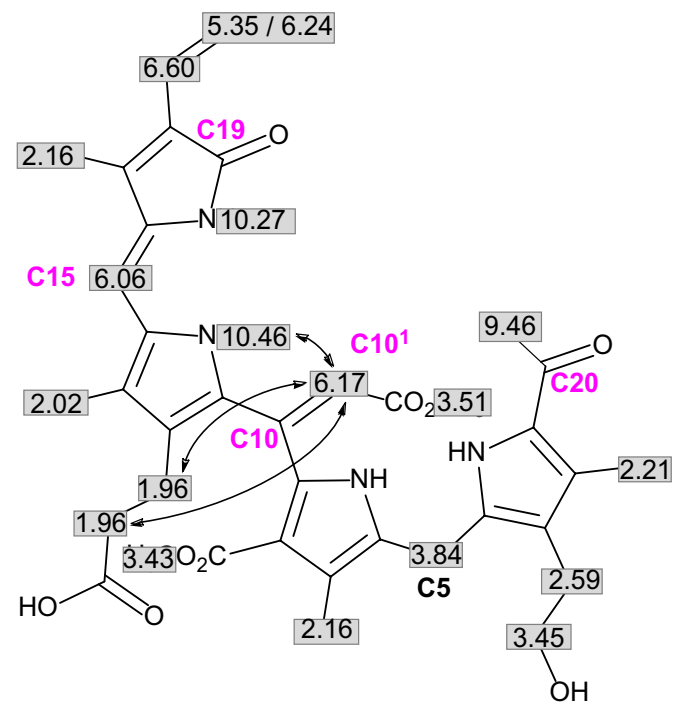

Fig. 6 NMR chemical shift data of the yellow biladiene 2 depicted in a graphical representation of the derived molecular constitution. Left: derived ${ }^{1} \mathrm{H}$ signal assignments and key correlations (arrows) from a ${ }^{1} \mathrm{H},{ }^{1} \mathrm{H}$-ROESY spectrum. Right: assignments of ${ }^{13} \mathrm{C}$ signals and of ${ }^{1} \mathrm{H}$

instable addition product 1-MeOH, which cleaves open to 2. The tertiary amine $\mathrm{NEt}_{3}$ accelerates the overall process, presumably via a critical deprotonation involved in the decomposition of the intermediate hemi-acetal function of 1-MeOH.

Besides the yellow biladiene $\mathbf{2}$ as the modestly stable major product (see Suppl. Mat. Fig. S8) of the methanolysis

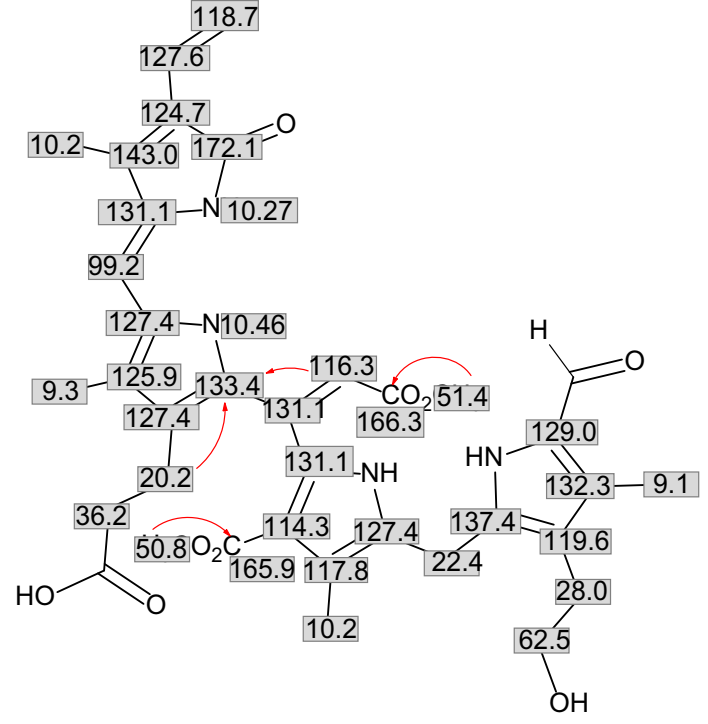

signals of two NH's, obtained from ${ }^{1} \mathrm{H},{ }^{13} \mathrm{C}-\mathrm{HSQC}$ and ${ }^{1} \mathrm{H},{ }^{13} \mathrm{C}-\mathrm{HMBC}$ spectra, and heteronuclear correlations (arrows), critical for defining the vinyl group $\mathrm{C} 10-\mathrm{C} 10^{1}$

of $\mathbf{1}$, two additional yellow tetrapyrrole fractions were also obtained from the decomposition of $\mathbf{1}$ in methanol and were characterized in a preliminary form. The UV-Vis spectrum of the polar minor product $3(9 \%)$ closely resembles the corresponding spectrum of $\mathbf{2}$ and exhibits an absorption maximum at $460 \mathrm{~nm}$ (see Fig. S4). In the ESI-MS of 3, pseudo-molecular ions $[\mathrm{M}+\mathrm{K}]^{+},[\mathrm{M}+\mathrm{Na}]^{+}$, and $[\mathrm{M}+\mathrm{H}]^{+}$ 


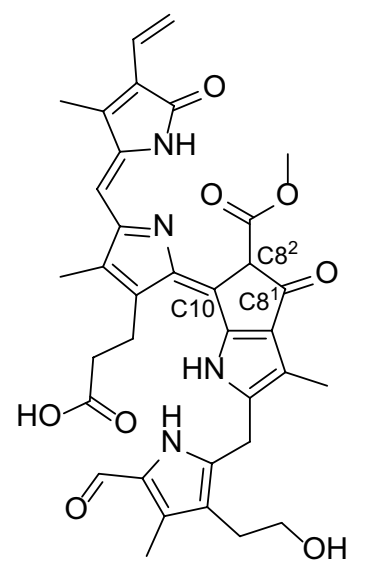

$\operatorname{PiCC} 1$

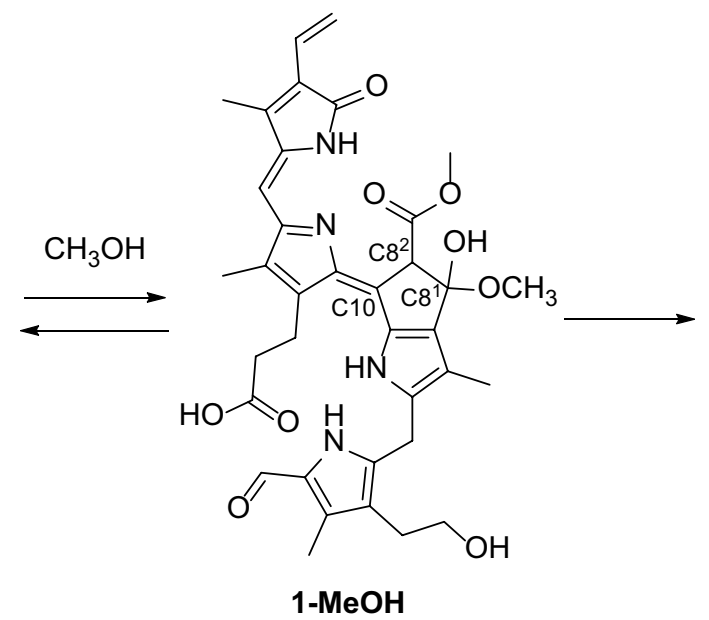

2

Fig. 7 Proposed mechanism of the retro-Dieckmann reaction of the PiCC 1, furnishing the yellow biladiene 2 , a ring E opened $8^{1}, 8^{2}$-seco-phyllobilin

were found at $m / z=697.1,681.2$, and 659.2, respectively, consistent with a molecular formula of $\mathrm{C}_{35} \mathrm{H}_{38} \mathrm{~N}_{4} \mathrm{O}_{9}$, from the formal addition of a $\mathrm{H}_{2} \mathrm{O}$ unit to PiCC (Fig. S5). A strong fragment at $m / z=615.3$ indicates a readily occurring decarboxylation, suggesting the presence of a second $\mathrm{COOH}$ group in this compound. The yellow tetrapyrrole $\mathbf{3}$ is, tentatively, deduced to possess the same framework as $\mathbf{2}$ and to carry a carboxylic acid group at C8 (rather than a methyl ester function) as a result of a hydrolytic version of the retro-Dieckmann reaction (Fig. 8).

The least polar yellow/reddish fraction (4) was isolated in raw yields of roughly $31 \%$ or $36 \%$ in the two experiments reported here. The UV-Vis-absorption spectrum of the isolated fraction 4 shows a maximum at $435 \mathrm{~nm}$ (Fig. S3), i.e., at a similar wavelength as the absorption maximum of typical phylloxanthobilins (at 420-440 nm). Its mass spectrum shows strong signals at $m / z=663.4$ and 641.3 , deduced to arise from $\left(\mathrm{M}+\mathrm{Na}^{+}\right)$and $\left(\mathrm{M}+\mathrm{H}^{+}\right)$, respectively. Hence, the tetrapyrrole $\mathbf{4}$ is suggested to have the molecular formula of $\mathrm{C}_{35} \mathrm{H}_{36} \mathrm{~N}_{4} \mathrm{O}_{8}$ and to be an isomer of $\mathbf{1}$. However, the observed strong signals at $m / z=1319.1\left(2 \mathrm{M}+\mathrm{K}^{+}\right), 1303.2$ $\left(2 \mathrm{M}+\mathrm{Na}^{+}\right)$, and $1281.1\left(2 \mathrm{M}+\mathrm{H}^{+}\right)$also indicate ions compatible with a dimer ( $2 \mathrm{M}$ ) of $\mathbf{1}$ (Fig. S6). In solution and in the crystal, some phylloxanthobilins, as well as the PiCC 1, (tend to) associate into non-covalent dimers [16, 23]. The available NMR data of the yellow tetrapyrrole $\mathbf{4}$ are compatible with an effectively single major structure (see Fig. S9). Unfortunately, several critical signals of the chemically rather labile 4 were broad and insufficiently resolved for the purpose of deducing its structure with confidence. However, the UV-Vis-spectral features of $\mathbf{4}$ indicate the effective interruption of the conjugated chromophore of the PiCC 1 at one of its unsaturated meso-positions, most likely at C10 (as, deduced from the NMR data, see Supp. Mat. and Fig.
S9). An intramolecular covalent addition of the carboxylate function to the carbon centre $\mathrm{C} 10$ would be compatible with such an isomer of the PiCC 1.

We describe here the readily occurring decomposition of the pink-coloured Chl-catabolite (PiCC) $\mathbf{1}$ [4, 10]. In a methanolic solution and at room temperature, the PiCC $\mathbf{1}$ degrades to the cross-conjugated yellow biladiene $\mathbf{2}$ as the major product, besides two incompletely characterized yellow linear tetrapyrroles. The yellow main product $\mathbf{2}$ is a formal retro-Dieckmann product from the decomposition of $\mathbf{1}$. The minor polar tetrapyrrole $\mathbf{3}$ presumably arises from a concurrent analogous reaction with water instead of methanol. The indicated readily occurring cleavage of the ring E moiety of the PiCC remodels the typical Chl-derived PB-skeleton in an unprecedented way by generating a corresponding bilin (Fig. 8). The reactivity described here for the (type-I) 1-formyl-19-oxo-bilin 1 appears to be typical for the pink PrBs. Indeed, a 1,19-dioxo-bilin-type PrB corresponding to the PiCC 1 and provisionally named a dioxobilin-type PiCC (DPiCC) has recently been described [17], which appears to suffer from similar instability in methanolic solution and formation of still uncharacterized yellow decomposition products. Thus, the here-reported findings may be relevant for PrBs from both major lines of the natural Chl-catabolites [24, 25], classified as type-I PBs and type-II PBs $[4,5]$. Hence, the ready degradation of the PiCC 1 to the yellow cross-conjugated biladiene $\mathbf{2}$, as well as to analogues, such as the diacid 3, suggests the opening of ring $E$ of the pink-coloured Chl-catabolites to represent a more generally relevant type of chemical transformation during natural Chlbreakdown in plants.

Remarkably, two now known degradative modifications of the first-formed 1-formyl-19-oxo-bilin-type (or type-I) PBs lead to bilin-type structures that lack the two 
Fig. 8 The cleavage of ring $E$ of phyllobilins generates bilin-type tetrapyrroles. Left: formulae of the phyllobilins PiCC 1 and DPiCC (shown in $Z, Z$ geometry). Right: formulae of the biladienes $\mathbf{2}$ and $\mathbf{3}$ ( $Z$ geometry) and of cysteine-bound phycoviolobilin (depicted with $Z, Z$ geometry) [21]

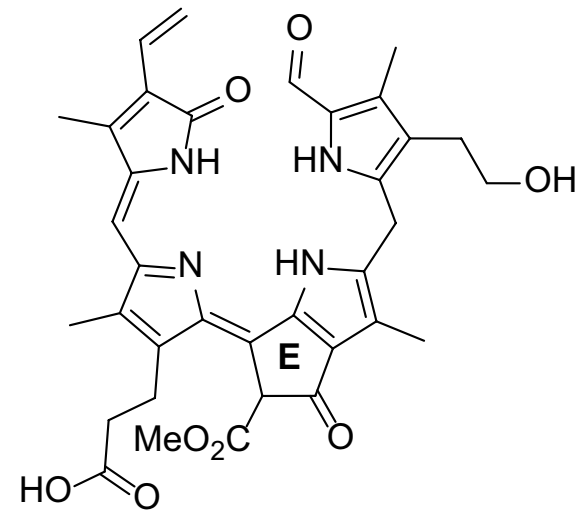

$\operatorname{PiCC} 1$

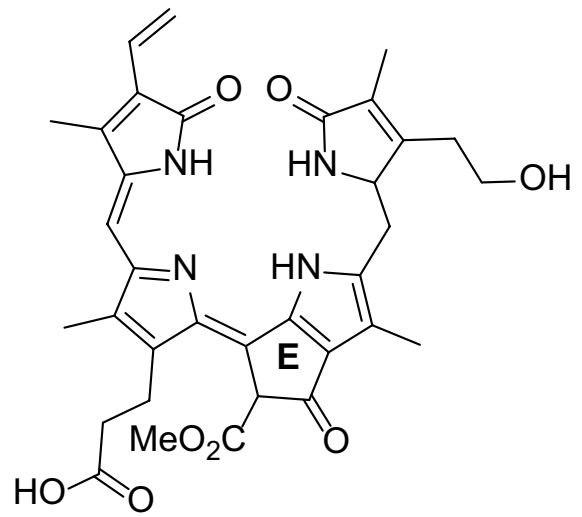

DPiCC<smiles>[R]OC(=O)c1c(/C(=C\C(=O)O)c2[nH]c(/C=C3\NC(=O)C(C)=C3C=C)c(C)c2CCC(=O)O)[nH]c(Cc2[nH]c(C=O)c(C)c2CCO)c1C</smiles>

biladienes $2(\mathrm{R}=\mathrm{Me})$ and $\mathbf{3}(\mathrm{R}=\mathrm{H})$<smiles>C=CC1=C(C)/C(=C/C2=N/C(=C\c3[nH]c(CC4NC(=O)C(C)=C4C(C)S[14C](C)(C)C)c(C)c3C)C(CCC(=O)O)=C2C)NC1=O</smiles>

phycoviolobilin (PVB) distinguishing hallmarks of the natural Chl-breakdown products (Fig. 8) [5]. One of these, the formyl group in the 1-formyl-19-oxo-bilins, is, in fact, the direct result of the key ring opening action of the enzyme pheophorbide a oxygenase (PaO) [26]. In some plants, this formyl group is removed subsequently by a cytochrome $\mathrm{P} 450$ (identified as CYP89A9 in Arabidopsis thaliana) that catalyses the oxidative deformylation, installing the second oxo-functionality of the type-II PBs [27]. The sterically congested $\beta$-ketoester moiety of the unique ring $\mathrm{E}$ of the natural PBs is another hallmark that is prone to a facile non-enzymatic disassembly at the stage of the pink phyllobilins, as shown here. In fact, non-enzymatic transformations may play surprisingly relevant roles in the natural Chl-breakdown, as first exemplified by the readily occurring acid-induced isomerization of the so-called fluorescent Chl-catabolites to their non-fluorescent isomers, the more abundant phyllobilanes (PBas) [24, 25].

The here-reported facile cleavage of ring $\mathrm{E}$ of $\mathbf{1}$ furnishes a cross-conjugated yellow biladiene, an unprecedented $8^{1}, 8^{2}$-seco-phyllobilin. The section C9-C10-C11 of the chromophore of $\mathbf{2}$ is proposed to alleviate steric strain by adapting a strongly non-planar conformation that leads to a reduction of $\pi$-conjugative overlap and further chemical lability of $\mathbf{2}$. Likewise, in the PiCC $\mathbf{1}$, and in other known phylloroseobilins (PrBs), this section has been deduced to be the source of peripheral steric strain that appears to contribute to their striking preference for the $10 E, 15 Z$-geometry $[10,17]$. The alternative, pseudocyclic 10Z, 15Z-arrangement is observed in $\operatorname{PrBs}$, when functioning as excellent and effectively tridentate chelate ligands for transition metals [16, 21, 28].

The unsaturated 'meso-carbon' $\mathrm{C} 10$ and the carbonyl carbon $\mathrm{C} 8^{1}$ of the PiCC 1 and of other PrBs are discussed here as electrophilic centres that should be considered sites of the covalent addition of (even weakly) nucleophilic species, such as water, hydroxyl and carboxyl groups, etc. Covalent addition of such functionalities, when provided by biological macromolecules, would contribute to an increased effective binding affinity with such macromolecular biomolecules. The specific covalent natural ligation of some related 'hemo'-bilins by protein-based cysteine residues is, in fact, crucial for the assembly of the photoswitchable chromophores in some bacterial photoreceptors [29]. 
The rapid degradation of the photoactive green Chls to colourless phyllobilins (PBs) has been suggested the key biological role of Chl-breakdown in plant cells undergoing senescence $[7,30]$. However, contrasting with proposals from earlier work [7], the PBs generated in higher plants are not seen any longer as mere waste products of a detoxification process $[4,5]$. Thus, the discovery of the natural yellow- and pink-coloured PBs induced a first, decisive, consideration of their possible biological function as coloured pigments [11, 31]. In more recent years, a number of biological roles have been suggested for the natural PBs [4, 32], e.g., in signalling [33, 34], as highly effective polar antioxidants [32, 35], as metal chelators $[21,28]$, as potential chromophores, and as inhibitors of the biosynthetic assembly of photoreceptors [4]. The striking blue luminescence of the colourless fluorescent Chl-catabolites [36], specifically of their persistent 'hypermodified' type (discovered in bananas [33, 37]), may serve the communication between plants and (frugivorous) animals $[4,36]$.

The degradation of the Chls in higher plants involves, roughly, 1000 million tons each year [1]. Thus, the natural Chl-breakdown via the $\mathrm{PaO} /$ phyllobilin pathway generates massive amounts of diverse PBs [7, 8], polar natural products with remarkable heterocyclic structures $[4,5$, 31 ], whose potential for a range of interesting biological roles should not be overlooked [23, 32, 38]. At various developmental stages, especially during leaf senescence [39] and fruit ripening [35, 40], plant cells are 'flooded' with Chl-catabolites. Hence, Chl-breakdown acts as a rich source of a range of specific heterocyclic natural products. Recent studies on physiological effects of some coloured phyllobilins in pharmaceutical and biomedical contexts [13, 41, 42] have boosted an interest for studying PBs in phyto-pharmaceutical and phyto-medical applications. The amazing enzymatic deformylation of the first-formed (type-I) formyloxo-bilins to type-II PBs and the facile non-enzymatic ring opening of the PiCC 1 involve the elimination of two structural characteristics distinguishing PBs from 'hemo'-bilins, thus specifically closing the structural gap between Chl-derived PBs and corresponding heme-derived bilins (Fig. 8) [3, 43]. The structural relationship between these two major classes of bilin-type compounds may represent a fundamental asset for plant life, and the two mentioned processes could be of specific interest as structural adaptations of PBs for bilin-dependent biological functions [5]. In fact, a recent report on 'tetrapyrrolic pigments from heme- and chlorophyll breakdown are actin-targeting compounds' draws attention to some remarkably similar physiological effects of phyllobilins and 'hemo'-bilins [42].

\section{Conclusion}

The facile chemical cleavage of a pink phyllobilin $(\operatorname{PrB})$ has revealed a reactivity of a typical PrB that extends the type of the processes known for the natural Chl-catabolites [6]. First considered mere waste products of the Chl-detoxification [7, 30, 44], the PBs are now recognized as novel heterocyclic natural products that, probably, are valuable not only for the plants that produce them [5,31-34], but also for animals and humans that feed on plant products $[35,45]$. Hence, in this respect, a fundamental change of paradigm has occurred [4], giving insights into the chemistry of PBs a new relevance when taking into account their possible biological roles [32]. Recent pharmacological studies with coloured PBs [41, 42, 46], furthermore, have begun inciting considerable interest for a range of specific applications in the pharmaceutical and biomedical areas. Hence, it is relevant to realize that some of the coloured PBs are conspicuously prone to further chemical transformations. Thus, the here-delineated cleavage of the PrB 1 to yellow bilin-type tetrapyrroles represents, on one hand, a remarkable metabolic path to compounds mimicking heme-derived bilins more closely. On the other hand, it may also help rationalize the typically low content of the PrBs, the so far 'last traceable' Chl-breakdown products, in senescent leaves. The barely touched and still enigmatic later 'downstream' processes of Chl-breakdown remain a field of unforeseeable discoveries.

\section{Experimental}

$\mathrm{MeOH}$ (HPLC grade) and MeCN (HPLC grade) from VWR (Leuven, Belgium); $\mathrm{H}_{2} \mathrm{O}$, deionized with Millipore S. A. S. Milli-Q Academic system $(18.2 \mathrm{M} \Omega \mathrm{cm}$, Molsheim, France); ACS reagent $\mathrm{KH}_{2} \mathrm{PO}_{4}$ and $\mathrm{K}_{2} \mathrm{HPO}_{4}$ from SigmaAldrich (Steinheim, Germany); Sep-Pak-C18 Cartridges (silica-based bonded phase with strong hydrophobicity), from Waters Associates (Milford, USA); PiCC 1 was prepared as previously reported [16].

UV-Vis spectroscopy: Varian Cary 60 spectrophotometer, $\lambda_{\max }$ in nm (rel. $\varepsilon$ ); ESI-MS: Finnigan LCQ Classic, $m / z$ (rel. intensity \%), ESI source, positive-ion mode, in $\mathrm{CH}_{3} \mathrm{CN} /$ aq. $\mathrm{NH}_{4} \mathrm{OAc}$, flow rate $2 \mathrm{~cm}^{3} \mathrm{~min}^{-1}$.

\section{Decomposition of PiCC 1 in methanol solution}

A solution of $5.8 \mathrm{mg} \operatorname{PiCC~} 1(9.1 \mu \mathrm{mol})$ in $58 \mathrm{~cm}^{3}$ of $\mathrm{MeOH}$ was purged with $\mathrm{Ar}$ for 5 min, then the flask was tightly stoppered, and the solution was stored under Ar at room temperature and in darkness for 19 days. A sample of $5 \mathrm{~cm}^{3}$ of the reaction mixture was removed for HPLC 
analysis of its further decomposition until day 47 (see Figs. S1 and S2). The remaining $53 \mathrm{~cm}^{3}$ of the reaction mixture were dried under reduced pressure, furnishing a dark brown residue. The residue was dissolved in a solvent mixture of $5 \mathrm{~cm}^{3} \mathrm{MeOH}$ and $6 \mathrm{~cm}^{3} 50 \mathrm{mM} \mathrm{K}$-buffer and loaded on a Sep-Pak cartridge ( $5 \mathrm{~g}$ ). The minor polar yellow fraction 3 was eluted first. Then, the major yellow fraction 2 was eluted by $\mathrm{MeOH} / 50 \mathrm{mM}$ K-buffer 55/45 (v/v). A third (yellow/orange) coloured fraction 4 was eluted by $\mathrm{MeOH} / 50 \mathrm{mM}$ K-buffer $=60 / 40(v / v)$. After desalting on a Sep-Pak $(0.82 \mathrm{~g})$ and drying under reduced pressure, fraction 3 was isolated as $0.48 \mathrm{mg}(9 \%)$ of a yellow residue. By an analogous work-up, $1.8 \mathrm{mg}$ (32\%) of the biladiene 2 were obtained as a yellow residue. The yellow/reddish fraction $\mathbf{4}$ was isolated as $1.9 \mathrm{mg}(36 \%)$ of a reddish residue. A small amount of the PiCC 1 was also re-isolated $(0.1 \mathrm{mg}$, calculated from UV-Vis spectrum).

\section{Decomposition of PiCC 1 in a solution of methanol with $0.08 \%$ of $\mathrm{NEt}_{3}$}

A solution of $6.5 \mathrm{mg}$ PiCC $1(10.2 \mu \mathrm{mol})$ in $65 \mathrm{~cm}^{3}$ of $\mathrm{MeOH}$ was purged with Ar for $5 \mathrm{~min}$. To the solution, 50 $\mathrm{mm}^{3}$ of $\mathrm{NEt}_{3}$ were added and the resulting solution was tightly sealed with stopper and stirred under Ar in the dark. After 8 days, the colour of the solution changed from red to yellow and an HPLC analysis indicated the disappearance of 1 (Fig. S3). The solution was diluted with $50 \mathrm{mM}$ K-buffer to $200 \mathrm{~cm}^{3}$ and applied to a $5 \mathrm{~g}$ Sep-Pak cartridge. The yellow fraction 2 was eluted first, with MeOH/buffer 55/45 (v/v), the yellow/reddish fraction 4 subsequently with $\mathrm{MeOH} /$ buffer $60 / 40(v / v)$. After desalting each fraction on a Sep-Pak $(0.82 \mathrm{~g})$ with washing down with $\mathrm{MeOH}$ and drying under vacuum, $3.4 \mathrm{mg}$ ( $53 \%$ yield) of the biladiene 2 were isolated as a yellow residue, and analogously, $2.0 \mathrm{mg}$ (ca. $31 \%$ yield) of $\mathbf{4}$ were obtained as yellow/reddish residue.

\section{Spectroscopic characterization of biladiene 2}

$\mathrm{UV}-\mathrm{V}$ is (in $3 / 2 \mathrm{MeOH} / 50 \mathrm{mM}$ potassium phosphate buffer, pH 7): $\lambda_{\max }($ rel. $\varepsilon)=462(1.00), 388(0.45), 314(0.93)$, $268(0.51), 208(1.03) \mathrm{nm}$; ESI-MS: $m / z(\%)=1426.0(28)$, $1391.1(10), 1390.2(20), 1389.1\left(18,[2 \mathrm{M}-\mathrm{H}+\mathrm{K}+\mathrm{Na}]^{+}\right)$, $1369.1(20), 1368.0(15), 1367.0\left(10,[2 \mathrm{M}+\mathrm{Na}]^{+}\right), 1347.3$ (10), $1346.1(12), 1345.1\left(16,[2 \mathrm{M}+\mathrm{H}]^{+}\right), 719.2(15), 718.3$ (55), $717.3\left(100,[\mathrm{M}-\mathrm{H}+2 \mathrm{Na}]^{+}\right), 697.3(15), 696.2(40)$, $695.4\left(70,[\mathrm{M}+\mathrm{Na}]^{+}\right), 675.2(10), 674.2(45), 673.3(85$, $\left.[\mathrm{M}+\mathrm{H}]^{+}\right), 642.3(9), 641.3\left(18,[\mathrm{M}-\mathrm{MeOH}+\mathrm{H}]^{+}\right)$; NMR: see Figs. 5 and 6, and detailed information in the Supplementary Materials; Tables S1 and S2 with lists of chemical shift values and signal assignments.
Supplementary Information The online version contains supplementary material available at https://doi.org/10.1007/s00706-022-02894-z.

Acknowledgements We thank Thomas Müller for help with mass spectrometric data. We are grateful to the Austrian Science Fund (FWF, Proj. No. P-28522) for financial support.

Funding Open access funding provided by University of Innsbruck and Medical University of Innsbruck.

Open Access This article is licensed under a Creative Commons Attribution 4.0 International License, which permits use, sharing, adaptation, distribution and reproduction in any medium or format, as long as you give appropriate credit to the original author(s) and the source, provide a link to the Creative Commons licence, and indicate if changes were made. The images or other third party material in this article are included in the article's Creative Commons licence, unless indicated otherwise in a credit line to the material. If material is not included in the article's Creative Commons licence and your intended use is not permitted by statutory regulation or exceeds the permitted use, you will need to obtain permission directly from the copyright holder. To view a copy of this licence, visit http://creativecommons.org/licenses/by/4.0/.

\section{References}

1. Hendry GAF, Houghton JD, Brown SB (1987) New Phytol 107:255

2. Kräutler B, Jaun B, Bortlik K, Schellenberg M, Matile P (1991) Angew Chem Int Ed 30:1315

3. Kräutler B (2014) Chem Soc Rev 43:6227

4. Kräutler B (2016) Angew Chem Int Ed 55:4882

5. Hörtensteiner S, Hauenstein M, Kräutler B (2019) Chlorophyll breakdown-regulation, biochemistry and phyllobilins as its products. In: Grimm B (ed) Metabolism: structure and function of plant tetrapyrroles, advances in botanical research, vol 90. Academic Press, London

6. Kuai B, Chen J, Hörtensteiner S (2017) J Exp Bot 69:51

7. Kräutler B, Matile P (1999) Acc Chem Res 32:35

8. Hörtensteiner S, Kräutler B (2011) Biochim Biophys Acta Bioenergetics 1807:977

9. Bortlik K, Peisker C, Matile P (1990) J Plant Physiol 136:161

10. Ulrich M, Moser S, Müller T, Kräutler B (2011) Chem Eur J 17:2330

11. Moser S, Ulrich M, Müller T, Kräutler B (2008) Photochem Photobiol Sci 7:1577

12. Li C, Erhart T, Liu X, Kräutler B (2019) Chem Eur J 25:4052

13. Karg CA, Doppler C, Schilling C, Jakobs F, Dal Colle MCS, Frey N, Bernhard D, Vollmar AM, Moser S (2021) Food Chem 359:129906

14. Wakana D, Kato H, Momose T, Sasaki N, Ozeki Y, Goda Y (2014) Tetrahedron Lett 55:2982

15. Vergeiner C, Ulrich M, Li C, Liu X, Müller T, Kräutler B (2015) Chem Eur J 21:136

16. Li C, Ulrich M, Liu X, Wurst K, Müller T, Kräutler B (2014) Chem Sci 5:3388

17. Li C, Kräutler B (2019) Monatsh Chem 150:813

18. Curty C, Engel N (1996) Phytochem 42:1531

19. Suzuki Y, Shioi Y (1999) Plant Cell Physiol 40:909

20. Ritter M, Oetama VSP, Schulze D, Muetzlaff K, Meents AK, Seidel RA, Gorls H, Westerhausen M, Boland W, Pohnert G (2020) Chem Eur J 26:6205

21. Li C, Kräutler B (2015) Dalton Trans 44:10116 
22. Woodward RB (1960) Angew Chem 72:651

23. Li C, Wurst K, Jockusch S, Gruber K, Podewitz M, Liedl KR, Kräutler B (2016) Angew Chem Int Ed 55:15760

24. Oberhuber M, Berghold J, Breuker K, Hörtensteiner S, Kräutler B (2003) Proc Natl Acad Sci USA 100:6910

25. Süssenbacher I, Hörtensteiner S, Kräutler B (2015) Angew Chem Int Ed 54:13777

26. Hörtensteiner $S$, Wüthrich KL, Matile P, Ongania KH, Kräutler B (1998) J Biol Chem 273:15335

27. Christ B, Süssenbacher I, Moser S, Bichsel N, Egert A, Müller T, Kräutler B, Hörtensteiner S (2013) Plant Cell 25:1868

28. Li C, Podewitz M, Kräutler B (2021) Eur J Inorg Chem 2021:1904

29. Rockwell NC, Martin SS, Lagarias JC (2017) Photochem Photobiol 93:741

30. Hörtensteiner S, Rodoni S, Schellenberg M, Vicentini F, Nandi OI, Qui YL, Matile P (2000) Plant Biol 2:63

31. Moser S, Müller T, Oberhuber M, Kräutler B (2009) Eur J Org Chem 2009:21

32. Moser S, Kräutler B (2019) Isr J Chem 59:420

33. Moser S, Müller T, Ebert M-O, Jockusch S, Turro NJ, Kräutler B (2008) Angew Chem Int Ed 47:8954

34. Moser S, Müller T, Holzinger A, Lütz C, Jockusch S, Turro NJ, Kräutler B (2009) Proc Natl Acad Sci USA 106:15538

35. Müller T, Ulrich M, Ongania K-H, Kräutler B (2007) Angew Chem Int Ed 46:8699

36. Mühlecker W, Ongania KH, Kräutler B, Matile P, Hörtensteiner S (1997) Angew Chem Int Ed 36:401
37. Banala S, Moser S, Müller T, Kreutz C, Holzinger A, Lütz C, Kräutler B (2010) Angew Chem Int Ed 49:5174

38. Karg CA, Schilling CM, Allmendinger L, Moser S (2019) J Porphyr Phthalocyanines 23:881

39. Vergeiner C, Banala S, Kräutler B (2013) Chem Eur J 19:12294

40. Moser S, Müller T, Holzinger A, Lütz C, Kräutler B (2012) Chem Eur J 18:10873

41. Karg CA, Wang PY, Kluibenschedl F, Muller T, Allmendinger L, Vollmar AM, Moser S (2020) Eur J Org Chem 2020:4499

42. Karg CA, Wang S, Al Danaf N, Pemberton RP, Bernard DJ, Kretschmer M, Schneider S, Zisis T, Vollmar AM, Lamb DC, Zahler S, Moser S (2021) Angew Chem Int Ed 60:22578

43. Falk H (1989) Chemistry of linear oligopyrroles and bile pigments. Springer, Vienna

44. Mühlecker W, Kräutler B, Moser D, Matile P, Hörtensteiner S (2000) Helv Chim Acta 83:278

45. Wang P, Karg CA, Frey N, Frädrich J, Vollmar AM, Moser S (2021) Arch Pharm 354:2100061

46. Karg CA, Wang P, Vollmar AM, Moser S (2019) Phytomedicine 60:152969

Publisher's Note Springer Nature remains neutral with regard to jurisdictional claims in published maps and institutional affiliations. 